\title{
Düşüncenin Seyri: Mantıktan Dile, Felsefeden Edebiyata
}

\author{
The Journey of Thought: From Logic to Language, \\ from Philosophy to Literature
}

\begin{abstract}
Mehmet Fatih DOĞRUCAN*
Öz: Felsefe disiplini ve düşünce faaliyetleri çoğunlukla, düşüncenin özneleri, nesneleri veya araçları hakkında düşünmüş, düşüncenin kendisi hakkında faaliyet gerçekleştirdiği zaman, bu faaliyet yüksek nitelikli bir entelektüel faaliyete dönüşmüştür. Düşüncenin kendisi hakkında düşünmek, onu belirginleştirmek, bizleri çoğu zaman mantık veya dil sahasına göndermiştir. Bu makale düşüncenin çözümlenme aşamasında mantık ve dil ile kurduğu ilişkiyi açıklarken, zaman içerisinde mantık sahasının yerini dil sahasına terk etmesini ve böylece mantığın sonucu olarak gerçekleşen felsefe faaliyeti yerine dilin sonucu olarak gerçekleşen edebiyat faaliyetinin ön plana çıkmasını açıklama amacını gütmektedir. Ayrıca bunun nedenleri ve sonuçlarını işaret edebileceği bir argümantasyon hedeflemektedir. Makalemiz mantık ilmine ait kategorilerin linguistik ilmine ait kategorilere dönüşmesini izah etmektedir.
\end{abstract}

Anahtar sözcükler: Felsefe, Mantık, Dil, Edebiyat

Abstract: The discipline of philosophy and cognitive faculties generally focus upon the subjects, objects and devices of (a) thought, and this cognitive faculty becomes something highly intellectual when thinking about the thinking itself occurs. Thinking about and concretizing the thinking process, generally induces people to dig deep in the fields of logic and language. This article firstly aims to clarify the relationship of thought with the logic and language which has been established by thought in the course of its resolution, then, in doing so, it focuses upon the fact that the field of language takes the place of logic over the course of time and thus a philosophical activity as a product of logic becomes displaced by a literary activity as a product of language. This paper also aims at indicating the causes and results of this process and it clarifies the course of the transformation of the categories of the field of logic into that of linguistics.

Keywords: Phylosophy, Logic, Language, Literature

\section{Düşünce Üzerine}

İnsanların, tarihin kadim çağlarından beri en az varlık ve ona ait bilgi kadar üstünde düşündüğü meselelerden bir tanesi de düşüncenin bizzat kendisi olmuştur. Düşünce faaliyetinin varlık üzerinde gerçekleşmesinin bir sonucu olarak ortaya bilgi süreci çıkmış, bu sürecin doğrulukyanlışlık, uygunluk, tutarlılık ölçütleri açısından denetlenmesi ise epistemoloji olarak tezahür etmiştir. Bütün bu faaliyetlerin temelinde mantık ilminin bir araç veya amaç olarak bulunup bulunmadığı da düşünce konusu olmuştur. Ancak düşünce ve kavramların faaliyetinin imkânı, kaynağ1 ve sınırları, özne ile nesne arasında gerçekleşen ilişsinin belirleyici etmeni haline dönüşmüş ve özellikle Descartes'ın açtı̆̆ 1 yol ile modernite ekseni (Touraine 1992, 337-345)

\footnotetext{
* Yrd. Doç. Dr., Akdeniz Üniversitesi, Edebiyat Fakültesi, Felsefe Bölümü, Antalya. mehmetfatihd@gmail.com
} 
düşünceyi, saf bir şekilde, öncelikle, kendi faaliyetinden dolayı üstünde düşündüğü veya düşüneceği her meselenin açıklayıcısı olarak görmüştür. Elbette ki, düşünce üzerine düşünmek, varlık veya bilgi üzerine düşünmek meselesinden daha kapsamlı ve yoğun bir faaliyet anlamına gelmektedir. Çünkü bizzat düşüncenin kendisi nesne olmak yerine artık bir öznedir. Böylece onun kendi nesneleri üzerinde inceleme ve araştırma zarureti ortaya çıkmıştır ki, bu durum tarihin başlangıcından bu yana, mantık, dil, söz, kavram, gibi temel düşünce nesneleri ile düşünceyi dış dünyaya bağlayan algı, olgu, madde gibi meselelerle de ilişkisinin incelenmesi anlamına gelmektedir.

Düşüncenin ilişkiye girdiği her uğrak nokta veya her bağlam, elbette ayrı ayrı bir inceleme konusudur. Her bağlam ile ilişkisini konu edinen birçok sistematik ortaya çıkmış ve bu sistematikler, düşüncenin ilişkiye girdiği merkezlerin ağırlığına göre felsefi ekolleri, akımları oluşturmuştur. Çok basite indirgeyip, detaya girmeyecek olursak, maddeyi merkeze alan düşünce faaliyetinin temelini materyalizm, aklı merkeze alan faaliyetin temelini rasyonalizm, algıyı ya da duyumu merkeze alan düşünme faaliyetinin temelini sensualizm, algı veya duyumu zihin ile epistemik bir ilişkiye sokan faaliyetin temelini ise empirizm gibi kavramlarla izah edebiliriz. Tabii ki işin içine durum veya konumuna göre diğer felsefi akımlar da girdiğinde, düşüncenin sistematize olduğu oranda, düşüncenin araçları veya amaçları meselesi ortaya çıkmaktadır. Lakin bizim konumuzun temelini düşüncenin dış dünya ile girdiği ilişkide elde ettiği tanımlar ve bu tanımları elde etme veya sergileme imkânı olarak kullandığı, nesneleri ilgilendirmektedir. Elbette ki tarihin kadim dönemlerinden bu yana, yani mitolojik dönemin ardından başlayan ve düşünce tarihi olarak okuyabildiğimiz dönemlerden bu yana, düşüncenin nesneleri olarak dil ve mantık anlaşıla gelmiştir. Çoğu zaman, sezgicilik veya rasyonalizm gibi birkaç felsefi akım müstesna, mantık veya dil, felsefenin sadece bölümü olarak değil aynı zamanda aleti olarak da kabul edilmiştir. Mesela Platonculuk buna örnek gösterilebilir. Hatta İbn-i Sina dil ve mantık alanını bazen felsefenin bölümü, bazen de aleti görebilmiştir (Emiroğlu 2003).

\section{Düşüncenin Mantık Yerine Dil ile Bağıntılanması}

Düşünce kavramı, faaliyet alanını, malik olduğu içerikleri sayesinde gerçekleştirir ki, buna çeşitli felsefi akımlar kendi çeşitli tanımlamalarıyla yaklaşmıştır. Mesela düşüncenin elbette ki en temel içeriklerinden birisi kavram meselesidir. Ancak kavram dediğimiz anda, farklı felsefi yaklaşımlara göre buna biçilen tanımlama da farklılık göstermeye başlamaktadır. Mesela kavram, salt akılsal açıdan ele alınarak ifade edilen bir şey olduğunda, İngilizcedeki gibi nosyon isimlendirmesi gibi bir tanımla karşılaşmamız mümkünken, algıların sonucunda Locke'un boş levhasını (zihin) (Locke 2000, 56) dolduran bir şey olarak tanımlandığı anda, konsepsiyon gibi bir isimlendirme biçimiyle karşı karşıya kalıyoruz. Çünkü Locke'un kavram olarak anladığı şey, tek başına veya herhangi bir şeye tekabül eden idelerden ziyade, onların birbiriyle olan bağıdır (Locke 2000,525) ve bu bağlar kavramın tek başına ele alınması yerine birbirleriyle anlam kazanacağı bir başlangıç sahasıdır. Yine Descartes'tan Berkeley’e uzanan çizgide kavram karşı1lığ olarak hem idea kelimesinin bükümünden elde edilen ide kelimesiyle de karşılaşıyoruz ki, bu kelime Locke'un düalistik anlama yetisini oluşturan yalın ideler ve karmaşık ideler olarak dil yetisini tanımlayan bir sürecin aleti olarak karşımıza çıkmaktadır. (Locke 2000, 133-153) Düşünce dediğimiz mesele tam da bu noktada kavramların birbiriyle bağıntılanma süreci anlamına gelmektedir. Kavramların birbirleriyle bağıntılanma süreci veya ilişkiye girme süreci, düşüncenin faaliyetini başlatan, adeta zembereğini oluşturan temel dinamo gibi görünmektedir. $\mathrm{Bu}$ sebeple Hegel, mantık bilimini, saf idenin bilimi olarak kabul edip, düşüncenin ve ona ait belirlenimlerin sahip olduğu yasaların açıklayıcısı (Hegel 1976, 104) olarak görmüştür. Mantık 
ilminin içeriği olan kavramlar ile dil bilimin içeriği sözcüklerin birbirini karşılayan duruma dönüşmesi, düşünce ile konuşma arasında bir özdeşlik olduğu fikrini de doğurur. Bu ilişkiyi yok saymamız ise mantık ile dilin işleyiş biçimini birbirinden metafizik manada ayırma anlamına gelecektir (Vygotsky 1985, 18). Kaldı ki felsefe disiplinlerinde düşüncenin içeriği olarak ide kavramının, son sistem felsefesi inşa etme çabasında olan Hegel tarafından düşüncenin soyut öğesi (Hegel 1976, 104) olarak ele alınması, ardından gelen filozofların, varlığı, dilsel olarak soyut biçimde karş1layan kavram veya sözcük gibi görevlerle birlikte düşünmesinin önünü açmıştır. Açıkçası anlaşılmaktadır ki, idelerin birbiriyle bağıntılanmasını mantık ilmi olarak anladığımız kadar, idelerin, dil-bilimsel (Linguistic) sözcük veya kavramlarla ilişkisi ve bu sözcüklerin de birbiriyle bağıntılanma ilişkisi, mantık ilminin hem sahasına girmeye, hem de mantık ilmini yeni metodolojiler veya kendisini mümkün kılacak arayışlara yöneltmeye başlamıştır. Bu sebeple idelerin zihinsel karşılıkları ve dil âlemindeki sözcüklere tekabülü Saussure açısından göstergebilim kuramıyla açıklanmaktadır. Saussure mantığın kavramlarla iş gördüğünü bildiği için somut-soyut, yalın-karmaşık gibi ikili bir doğaya sahip olduğunu (Saussure 2014, 33-35) ve bunun ise gösteren-gösterilen ilişkisinden mürekkep göstergebilim olduğunu açıklamaya çalışır. Bu durumlar ve bahsettiğimiz isimler alet olmaktan bakımından mantık ilmi yerine dil süreçlerinin kabul görmesine uzanan sürecin ilk örnekleri gibi kabul edilebilir. Ancak yine de bundan önce, düşünce ile dış dünya arasındaki ilk epistemik bağıntılanma sürecine mantık yerine dili oturtma çabaları, ortaçağ süresince nominalistler ve kavram realistleri olarak karşımıza çıkmıştır. Aralarındaki çatışma ilerleme sürecini mümkün kılmış ve metodolojik olarak akıl ürünlerini tanımlama çabaları, Descartes ve Hobbes ile başlayıp Locke ile detaylanan zihin sürecini mümkün kılmıştır.

Günümüzde de mantık ilminin alt yapısını ise yine buna benzer zıtlıklar ve ilişkiler ağından bağıntılanma biçimleri oluşturmaktadır ki, böylece mantık ilmi semiotik süreçlerle aynı işlevi gerçekleştiren bir noktaya taşınmıştır. Mesela mantık ilminin bir zamanlar dedüktif metodoloji ile anlama yönelmesinin yerini semantik, endüktif metodoloji ile beraber ihtimaller ve yapıların doğasını araştırmanın yerini sentaktik, analojik metodoloji ile benzerlik ilişkisi çerçevesinde bağıntı kuran ve esnemeye açık tasımın yerini ise pragmatik çok anlamlılık (edimbilim) almaya başlamıştır. $\mathrm{Bu}$ durumu biraz daha açmak gerekirse öncüllerden sonucu zorunlu olarak çıkarsayan dedüktif yöntem yerine göstergelerden anlamı çıkarsayan semantik, deney dizimi veya genellemeye ulaşan dizilim ile sonuç elde eden endüktif yöntem yerine, söz dizilimi ile sonuç elde eden sentaktik, nesnel ve öznel benzerliklerin ilişkisinden hareketle sonuç elde eden analojik yöntem yerine, semboller ve işaretlerin kullanıcılarla ilişkisini inceleyerek sonuç elde eden pragmatik ön plana çıkmıştır.

Esasında bu durum, modernitenin, kesin bilgi arayışı sebebiyle çıktığ 1 yolda, kesin ve kabul edilmiş doğrulara ulaşma zorluğu yaşaması veya bilgiyi kesinleştirme faaliyetinin zaman alması ve sekülerleşen bilgi anlayışı gereğince kabullerin yerine, zorunlu olarak olasılıkları merkeze almasıyla başlayan bir süreçti. Böylece mantığın değişmez ve şaşmaz tutarlılık arayışına sebep olan işleyiş yerine, dil-bilimsel kuralların işleyişi, düşüncenin meydana geliş sürecinde bağıntı olmaya ve birbirinden farklı düşünce öbeklerini, birbirine öncül ve sonuç ilişkisi içinde bağlamaya başlamıştı. Böylece olasılıkların çok yönlü oluşu, mantığın esnemez doğası yerine dilin, bazı bağıntı ve ilişkiler sayesinde esneyebilen doğasına dönüşmeye başlamış ve mantıki çıkarımların işleyiş biçimi yerine dilsel anlamın işleyişinden doğan çıkarımların sanki mantık imiş gibi bağıntıya yerleşme durumu söz konusuydu. Böylece düşüncenin aleti olarak düşünülen mantık yerine, düşüncenin ifadesi olarak düşünülen dil kuramları mantığın tahtına çoktan yerleşmişti. 
Aslında bu durum yani üst paragrafta bahsettiğim dönüşüm, düşünce kavramının başından sonuna kadar oluşmasında rol oynamıştır. Düşünceyi denetleme yeteneğinde bulunan mantık ilmi yerine, sadece oluşmuş bir düşünceyi kendi oluş sürecini takip eden kelimeler ve cümleler bütünüyle diş dünyaya aktaran dilsel sürece dönüşme durumu, ise bu dönüşümün kendisi olarak anlaşıldığı kadar, zihin dünyasının kurgusal olarak dış dünya ile ilişki kurması olarak da anlaşılmalıdır. Çünkü cümle veya tümce ne dersek diyelim, gerçekliğin açık bir tasarımı veya betimlenmesi (Wittgeinstein 2003, 49) olarak mantıktan farklı biçimde, onu, anlamaya çalışmanın yolu değil, kurgulamanın yoluydu. Açıkçası modernitenin hızlı ve sürekli doğası, bilimsel alanlardan sosyal alanlara kadar süratli devinim içinde seyretmesi, düşüncenin işleyişi ve sonuçlanması açısından, mantık yerine dil-bilimsel çözümlemeleri kanıksamış ve sanki daha çabuk sonuca ulaşmaya başladığını düşünme eğilimi göstermiştir. Bunun altında yatan en önemli etmenlerden bir tanesi bilimsel gelişimin sebep olduğu hızlı ve takip edilemez noktaya ulaşan teknoloji ve bunun sonucunda gerçekleşen hızlı bir sosyal devinimin ekonomik manada tüketici talebi olarak görülebilir. Bu hızlı gelişimin sonuçlarının denetlenemeyecek kadar süratli olması ve bilimsel gelişimin ekonomik değere dönüşmesi sonucu ortaya çıkan sabırsız tüketiciler kitlesinin devamlı gelişime açık doyurulamaz açlığ 1 sonucunda düşünce mekanizması da hızlı karar vermeli, düşüncede denetlenebilir bir doğruluk yerine hızlı ve faydalı bir uzlaşılabilirlik kavramı ön plana çıkmalıydı. İşte tam da bu sebeple uzlaşımın temel aracı olan dilsel süreçler, mantık yerine mantık imiş gibi bir işleve sahip olmaya başlamıştır.

Artık genel talep ve ilim sahası gözlemlediğim kadarıyla, dilsel sürecin etkinliği sebebiyle, mantık için gereken öncüllerin bilgi açısından kesinliği, tutarlılığı veya çıkarımdan doğan anlamlılığı ile ilgilenmek yerine, dilsel süreçteki anlam yapısı, sözsel dizilim süreci veya esneyebilen doğası gereğince pragmatik anlam çokluğu açısından faydalı kullanıma dönüşüp dönüşmeyeceği meselesiyle ilgilenerek, bu sayede düşüncenin kesinleşmesi yerine, bir sonraki aşamaya geçip geçemeyeceği ve bu yolla proaktif olup olamayacağ meselesiyle ilgilenmektedir. Yani kesinleşen bir bilgi sürecinden daha çok, kesinleşmesine ihtiyaç duyulmaksızın kullanılabilir ve o anlık pratikmiş gibi iş görebilir teori sahaları, yasalaşmamış entelektüel faaliyetler veya sonuçları tamamıyla test edilmemiş bilimsel buluşlar, dilsel sürecin pazarlama ve kullanım sahasında mantık ilminin ortaya koyacağından farklı ivme kazanmaktadır. Dilsel süreçler, bir önceki cümlede saydığımız meseleleri, bu noktada derin analitik yerine ikna ve kullanıma sokma konusunda işlev elde etmektedir. Açıkçası düşüncenin metodolojisi olarak mantık yerine dilbilim çözümlemesinin pratik bazı sonuçları olduğu gibi, birtakım kırılmalara da yol açmıştır.

\section{Mantıkmış Gibi Kullanılan Dilbilimin Yarattığı Kırılma}

Ele aldığımız bu mesele, yani mantık işlevselliği yerine dilbilim işlevselliğinin düşünce metodolojisinde yer tutması, bir takım bilimsel, sosyal ilerlemeler ve onların kabul edilebilirliği veya erişilebilirliği açısından kolaylık sağlamış olsa da, birtakım kırılmalara da sebebiyet vermiştir. $\mathrm{Bu}$ kırılmalar, öznel veya toplumsal alg1 dünyasının değişiminden başlayarak birbirinden farklı kültürlerin alg1 sahasına kadar takip edilebilir. Öncelikle kırılma sahası mantığın kullanışlılığı açısından başlamıştır. Mesela doğa bilimlerinin işleyiş skalasını belirleyen mantık ilmi, sosyal bilimler söz konusu olduğunda esnekliğini kaybetmiştir. Çünkü Heinrich Rickert'a göre doğa bilimleri genelleştirici kavramlarla iş görürken, sosyal bilimler ise bireyselleştirici kavramlarla iş görmektedir (Sayın 2014, 34). Doğa bilimlerinin genelleştirici tavrı, kullandığı mantık sahasının evrensel doğasıyla etkileşim kurarken, sosyal bilimler ise bireyselleştirici tavrı alt yapısında bulundurduğu dilsel süreçlerin yoruma açık doğası sebebiyle gerçekleştirmektedir. Mantık ilminin evrensel doğası yerine dilsel süreçlerin yoruma açık 
doğası, bilgi edinme adına gerçekleşen faaliyetlerden, siyaset kültürüne kadar birçok noktada farklılaşma veya kırılma yaşattı. Fakat mantık ilminin sıklıkla praksis alanıyla yani pratik sahada kullanılmasının değersiz olduğu düşüncesi (Taylan 1988, 15) onu saf bir ilim olarak inceleme çabasını doğurmuştur. Lakin mantık ilminden son süreçlerle beraber dilsel süreçlerin ve dilbilimin anlaşılması ise, artık bunu pratik saha içerisinde değer atfederek tanımlamaya başlamıştır. Çünkü dil tamamen pratiklerin formelleşmiş bir biçimi olarak belirmektedir. Mantık, bilginin elde edilişsürecinde, yani bilen ile bilinen arasındaki alakayı tespit eden bir metot olarak (Taylan 1988, 17) böylece yerini dilbilim kuramının gösteren ile gösteren arasındaki ilişki sürecine dönüşmüştür. $\mathrm{Bu}$ durum ise göstergebilim kavramıyla açıklanmaktadır. Böylece mantık ise genel anlamıyla göstergebilim yerine kullanılan başka bir sözcüğe dönüşmüş olmaktadır (Guiraud 2016, 18).

İşte tam da bu sebeple bilginin elde ediliş biçimi, imkânı, kaynağı, sınırları gibi bir düşünme sahası olan epistemoloji kavramı bu açıdan kırılma yaşadı. Çünkü felsefe geleneği sebebiyle üstünde yüz yıllarca düşünülmüş tartılmış veya sarf edilmiş fikirler, mantık yerine dilsel sürecin etkinliğiyle beraber kesinlik erdemini mümkün kavramına terk etmeye başladı. Bu ise kesinlik amacındaki mantık temelli açıklamalar yerine kesinlik ihtiyacını sadece kendine araç kılan retorik temelli açıklamalara uzandı. Böylece mantığın evrensel doğası yerine argümante ediliş biçimini, bizzat hatibi (Altınörs 2015, 28), belirlemeye başladı. Çünkü bilen ve bilinen ayrımı yerine gösteren ve gösterilen kavramı, bilginin evrensel doğası ve onu sağlayacak metot yerine göstergenin yorumlanabilir doğasını ön plana aldı ve hatip olan ise göstergenin sahibine dönüşmeye başladı.

Elbette ki düşünceyi, mantık metodolojisi yerine dil-bilim yapısıyla açıklayan, çözümleyen ve bu yolla bilgiye ulaşma sürecinin bir metodolojiye dönüşmesi, zaman içerisinde mantık ilminin bir ürünü felsefe yerine, dilsel süreçlerin bir ürünü olan edebiyat sahasını, entelektüel faaliyetlerin temeline oturtmaya başlamıştır.

Böylece insanlık, bilgi edinme, düşünce konusunda pratik yapma, tutarlı çözümlemeye ulaşma konusunda, kendilerine tatsız ve zahmetli gelen felsefe yerine daha eğlenceli ve estetik çekiciliği bulunan edebiyat ile çözümleme noktasına başvurmaya yönelmişlerdir. Aslında bu durum önceki başlıklarda ifade ettiğim üzere, sosyal hayatta sonuca odaklı pratik bir hız kazanma pragmatizmi üzerine gerçekleşmeye başlamıştı ki, pratik açıdan değersiz görülen mantık (Taylan 1988, 15) bizzat kendisi bir pratik olan dil sahası ile görünüşe çıkmaya başliyordu. Artık bilgi edinme sürecinde mantığın ürünü felsefe yerine, dilin ürünü edebiyat entelektüel bir değer kazanmıştı. Hatta felsefe ve dil sahası o kadar birbiri ile iş göremez halde ele alınmıştı ki, "felsefi problemler, dil tatile gittiği zaman ortaya çıkar" (Wittgeinstein 2000, 34) yani dil sahasının işlevsel olarak hâkim olduğu yerde felsefe ve metodik alanına ihtiyaç kalmaz biçimde bir çıkarım hakim olmuştur. Wittgeinstein'dan anlaşılan veya ona izafi edilebilen bu çıkarım ile pozitivist bir bilim algısı desteklenmek istenirken, dilin göreceli doğası, izafiyete yatkınlığı dili bilgi edinme sürecine yerleştirmiştir. Böylece dil ve dil oyunlarının ürünleri bilgi sürecinin temeli olacaktır. Ancak yine de bu noktada bir dil ürünü olan edebiyatın bilgi edinme sürecinde kullanılıyor oluşu dahi onun göreceli yapısını ortadan kaldırmamaktaydı. Bu sebeple yine mantık imiş gibi dilsel süreçlere başvurarak, pragmatist felsefe sınırları içerisinde göreceliliğin meşrulanması (Sarup 1997, 10) gerekiyordu. Bu sayede edebiyat ve onun roman, şiir, tiyatro hatta son tahlilde sinema gibi ürünleri, özellikle, siyasetten sosyolojiye, psikolojiden doğa bilimlerine kadar birçok noktada bilgi aktaran veya bilgi için başvurulan, hatta bilgiyi muhakeme eden ve denetleyen bir alana dönüşmeye başladı. Artık derin bilimsel tahliller ile çözümlenmiş "İstanbul'un Fethi" meselesi için başvuru noktaları, 
bilimsel makaleler veya felsefi arka plan yerine herhangi bir sinema veya tiyatro eseri üzerinden basit ve pratik manada daha anlaşılır hale dönüşmesi ve bunun tercih ediliyor oluşuydu.

Aslında mantık ilminin yerini dilsel süreçlere bırakması, anlam sorunu açısından felsefe yerine edebiyat sahası ile iş görmeye başlamak anlamına gelmektedir. $\mathrm{Bu}$ durum dilsel süreçlerin bir iletişim aracı olarak tanımlanması gerçeğini değiştirmemektedir ki, bu durum Jean Baudrillard' $n$ ifade ettiği “...Anlam ve anlama ait içeriklerin tümünün egemen bir iletişim aracı tarafindan yutulmast..." (Baudrillard 2005, 119) meselesini ortaya koymaktadır. Dilin iletişimsel yönü düşüncenin aktarımı ve farklı akıllar tarafından elde edilmesi sürecinde pratik bir saha olarak hız kazandırmaktadır. Bu ise basit ve hızlı biçimde bilgiye, en azından tüketim amacıyla ulaşmanın yeni bir versiyonuydu. Kaldı ki, ilerleme çağı için kalıcı mantık yasaları olabilirdi, ama kalıcı ve değişmeyen türden bir bilgi anlaşılır bir şey değildi. Analitik evren, sonsuza kadar denetlemeye tabii öncüller veya veriler ile oluşan bir süreklilik arz ediyor ise bilginin aynı kalma durumu elbette mümkün değildi. O halde hazır olduğu kadarıyla tüketmek ve bunun sağlayacağı pragmaya ulaşmak birincil yoldu. Bu sebeple değişen teknoloji ile elde edilen birçok bilgi, sebepleri veya sağlaması yapılmadan, sonuçları hesaplanmadan tüketim metası haline dönüştü. Mesela cep telefonlarında uzun ömürlü olması hasebiyle üretilen lityum piller sebep olduğu sonuçlar incelenmeden yeni ve daha kullanışlı teknolojinin icadıyla beraber kullanımdan kalktı.

Pekala o halde basit ve hızlı bilgiye ulaşma sürecinde metodolojik olarak bu kırılmanın sonuçları nerelerde gözlenmeye başlandı? Öncelikle işe yarar bilgi kavramını önemseyen sosyal bilimsel alt disiplinler, bu sayede temel disiplinlerin üstüne çıkmaya başladı. Mesela sosyoloji veya psikoloji gibi temel disiplinlerin devasa kritikleri yerine, onları sadece belirli bir amaç için kullanan ve alt disiplin hüviyetindeki iletişim bilimlerinin bu iki temel disiplinden daha fazla önemsenmesinin yolunu açtı. Kaldı ki, bu sadece beşeri ilimler için değil doğa bilimleri gibi sahalar için de geçerlidir. Ancak özellikle siyasetten ahlaka kadar sirayet edilen her ilim sahasında, sadece yarar sağlayacağı kadar draje haline getirilmiş sosyoloji ve psikoloji ilminden harmanlanmış iletişim bilimleri sayesinde, o günlük problem çözen ve hızlı üretilen bilgi ve uygulama dağarcı ğı, pratik alanın göbeğine yerleşmeye başladı. Elbette bu durum derinlemesine analiz edilen sonuçlar yerine elde edilmiş fayda durumunu önemsedi ve sonrasında oluşabilecek olumsuzlukları ise yine kesinlik yerine ihtimaller zincirinde görerek öteleme yolunu seçti.

Bunun sonucunda mantık tasarımları ve kesinlik araştırması yerine retorik ve temel argümanı olan ikna kavramı merkeze oturmaya başladı. Entelektüel görüşler, ilimsel düşünceler, bilimsel ispatlar, kendisini mantık argümanlarıyla denetleyip kesinleştirmek yerine, kendisini mümkün kılan yol olarak propaganda veya alg1 süreçleriyle iş görmeye başladı. Ancak dilbilimsel kuramlarda hala daha önemini koruyan Ferdinand De Sassure, dil bilimsel meselelere yukarıdaki kırılmaları yaratacak tarzda yaklaşan bazı dilcileri, şu sözlerle eleştirmektedir. "Dilin olmuş-bitmiş soyut bir şey değil de olmakta olan somut bir şey olduğu bahanesiyle, dilbilimde bu sağlıkl matematiksel mantıktan vazgeçebileceğini sanmak, kanımızca, başlarda Cermen aklının doğuştan esinlemiş olduğu derin bir yanılgıdır" (Saussure 2014, 48). Bu tarz bir dilsel yaklaşım, sosyoloji, psikoloji başta olmak üzere insani bilimlerin her alanında birtakım kırılmalar yarattığı gibi ifade ediliş süreci üzerinden de diğer doğa bilimleri ve teknik bilimler sahasını da etkilemiştir.

Bunun sonuçlarını, yani mantık sahasının dilsel süreçlere dönüşmesinin veya mantık olarak dilbilimsel işleyiş biçimlerinin anlaşılması ve bilgi etkinliğinde felsefe yerine dil ürünlerinin ön plana çıkmasının sonuçlarını, ilişkili olduğu ve metodik olarak etkilediği tüm ilimler için araştırmak, ayrı bir makale konusudur. Özelikle sosyoloji, psikoloji, iletişim bilimleri, 
Antropoloji gibi sahalarda yarattığı kırılmalar, bu saydığımız ilimlerle, dolaylı ya da dolaysız yoldan alakalı ilimleri de etkilemiştir. İşte bu sebeple bunun yönünü tayin etmek ayrı bir makale konusudur.

\section{KAYNAKÇA}

Altınörs A. (2015). Dil Felsefesi Tartışmaları (Platon'dan Chomsky'ye). İstanbul 2015.

Baudrillard J. (2005). Simularklar ve Simulasyon. Çev. O. Adanır. Ankara 2005.

Emiroğlu İ. (2003). "Mantık/TDV" Türkiye Diyanet Vakfi İslam Ansiklopedisi (Cilt 28) 19-28. İstanbul 2013. Kaynak: http://www.islamansiklopedisi.info/dia/pdf/c28/c280018.pdf

Guiraud P. (2016). Göstergebilim. Çev. M. Yalçın. Ankara 2016.

Hegel G. W. F. (1976). Bütün Yapıtları (Seçmeler)-1. Çev. H. Demirhan. Ankara 1976.

Locke J. (2000). Insanın Anlama Yetisi Üzerine Bir Deneme. Çev. M. D. Topçu. Ankara 2000.

Sarup M. (1997). Post-Yaptsalcllık ve Post-Modernizm. Çev. A. Güçlü. Ankara 1997.

Saussure F. (2014). Genel Dilbilim Yazıları. Çev. S. Kılıç. İstanbul 2014.

Sayın Ö. (2014). Göstergebilim ve Sosyoloji. Ankara 2014.

Taylan N. (1988). Mantık (Tarihçesi, Problemleri). İstanbul 1988.

Touraine A. (1992). Modernliğin Eleştirisi. Çev. H. Tufan. İstanbul 1992.

Vygotsky L. S. (1985). Düşünce ve Dil. Çev. S. Koray. İstanbul 1985.

Wittgenstein L. (2000). Felsefi Soruşturmalar. Çev. D. Kanıt. İstanbul 2000.

Wittgenstein L. (2003). Tractatus Logico Philosophicus. Çev. O. Arıoba. İstanbul 2003. 